\title{
Central sympathetic inhibition: a neglected approach for treatment of cardiac arrhythmias?
}

\author{
Francesca Cagnoni ${ }^{1,2}$, Maurizio Destro ${ }^{1}$, Erika Bontempelli ${ }^{1}$, Giovanni Locatelli ${ }^{1}$, Dagmara \\ Hering $^{2}$, Markus P. Schlaich ${ }^{2}$
}

\begin{abstract}
${ }^{1}$ Internal Medicine Ward and Hypertension Centre, Department of Medical Science, Azienda Ospedaliera of Treviglio (BG), Italy; ${ }^{2}$ Dobney Hypertension Centre, School of Medicine and Pharmacology - Royal Perth Hospital Unit, University of Western Australia, Perth, Australia.
\end{abstract}

Word count: 5075 words (excluding references)

Correspondence to:

Professor Markus Schlaich

Dobney Chair in Clinical Research

School of Medicine and Pharmacology - Royal Perth Hospital Unit

The University of Western Australia

Level 3, MRF Building, Rear 50 Murray St,

Perth WA 6000; Australia

Phone: +61 892240334 Fax: +61 892240374

email: markus.schlaich@uwa.edu.au 


\begin{abstract}
Atrial fibrillation (AF) is the most common sustained cardiac arrhythmia. Over-activation of the sympathetic nervous system (SNS) plays an important role in the pathogenesis of comorbidities related to AF such as hypertension, congestive heart failure, obesity, insulin resistance, and obstructive sleep apnea. Methods that reduce sympathetic drive, such as centrally acting sympathoinhibitory agents, have been shown to reduce the incidence of spontaneous or induced atrial arrhythmias, suggesting that neuromodulation may be helpful in controlling AF. Moxonidine acts centrally to reduce activity of the SNS and clinical trials inidcate that this is associated with a decreased AF burden in hypertensive patients with paroxysmal AF and reduced post-ablation recurrence of $\mathrm{AF}$ in patients with hypertension who underwent pulmonary vein isolation (PVI). Furthermore, device-based approaches to reduce sympathetic drive, such as renal denervation, have yielded promising results in the prevention and treatment of cardiac arrhythmias. In light of these recent findings, targeting elevated sympathetic drive with either pharmacological or device-based approaches has become a focus of clinical research. Here we review the data currently available to explore the potential utility of sympatho-inhibitory therapies in the prevention and treatment of cardiac arrhythmias.
\end{abstract}

Keywords: AF, arrhythmia, SNS, sympathetic, denervation, moxonidine 


\section{Introduction}

Atrial fibrillation (AF) is the most common sustained cardiac arrhythmia. In 2010 the estimated number of affected individuals worldwide was 33.5 million, including 20.9 million males and 12.6 million females. The burden associated with AF increased by $18.8 \%$ in males and $18.9 \%$ in females from 1990 to 2010. The estimated age-adjusted incidence rate is 60.7/100,000 person-years in males and 43.8 in females. Mortality associated with AF was higher in females, and increased by 2-fold and 1.9-fold in males and females, respectively, from 1990 to 2010.

In most patients there appears to be an inexorable progression from paroxysmal AF to persistent or permanent forms. Some advances have been made to better understand the development of AF from its preclinical state as an "arrhythmia-in-waiting" to its final expression as an irreversible and endstage cardiac arrhythmia associated with serious cardiovascular adverse events. Nonpharmacological interventions to control the occurrence of AF or to limit its expression have been developed in the past decade. Ablation techniques, usually pulmonary vein isolation (PVI), have proven successful in the treatment of $\mathrm{AF}$, particularly by reducing the symptomatic burden associated with the arrhythmia.

It is well known that sympathetic nervous system activation can induce significant and heterogeneous changes of atrial electrophysiology and induce atrial tachyarrhythmias, including atrial tachycardia (AT) and atrial fibrillation $[2,3]$. Methods that reduce sympathetic drive have been shown to diminish the incidence of spontaneous or induced atrial arrhythmias. In this review we focus on the relationship and therapeutic opportunities associated with inhibition of sympathetic nervous system activity in the context of atrial fibrillation.

\section{The pathophysiological role of SNA in developing arrhythmias}

The human heart has a rich autonomic innervation composed of vagal nerves and ganglion cells, located either outside (extrinsic) or inside the heart (intrinsic), and both are crucial for cardiac functioning and arrhythmogenesis [2, 4, 5]. Extrinsic sympathetic nerves originate from the paravertebral ganglia, including the superior cervical ganglion, middle cervical ganglion, the thoracic ganglia and mostly the stellate ganglion, a major source of cardiac sympathetic innervation. The intrinsic cardiac nerves are found mostly in the atria, and are considered the ones mainly involved in atrial arrhythmogenesis [6]. The stellate ganglion connects with multiple intrathoracic nerves and structures as well as skin [7-10]. Most of the ganglion cells within the stellate ganglion (> 90\%) are positive for tyrosine hydroxylase $(\mathrm{TH})$, the enzyme responsible for synthesis of 
catecholamines. However, some ganglion cells are negative for TH but stain positively for choline acetyltransferase [11]. Similar findings regarding TH staining are found in the thoracic vagal nerves [12]. Further, vagal nerve recordings in dogs showed that isolated vagal nerve activation can induce tachycardia, perhaps consistent with activation of the sympathetic components [13].

Histological study of the human pulmonary vein (PV)-left atrium (LA) junction [14] has shown that numerous autonomic nerves are present. The highest nerve density is found in the left atrium within $5 \mathrm{~mm}$ of the PV-LA junction, and nerve density is higher in the epicardium than endocardium. Adrenergic and cholinergic nerves are closely bound together at tissue and cellular levels. This close co-localization makes it difficult to perform radiofrequency catheter ablation that selectively eliminates sympathetic or parasympathetic neural influences. Furthermore, cardiac autonomic innervation is subject to constant remodelling. Anatomical examinations of diseased hearts by Vracko et al. showed findings consistent with cardiac neural remodelling $[15,16]$. Cao et al. injected nerve growth factor (NGF) into the left stellate ganglion and induced cardiac nerve sprouting in normal canine hearts [17]. Zhou et al investigated the mechanisms of nerve sprouting in a canine model of myocardial infarction and showed a persistent elevation of NGF levels in aorta and coronary sinus within 1 month after infarction. NGF was transported retrogradely to the left stellate ganglion through axonal transport and triggered nerve sprouting in the non-infarcted ventricles and atria [18]. Increased atrial sympathetic innervation was associated with increased incidence and duration of AF in those animals. These studies show that, while cardiac injury may be limited to the ventricles, neural remodelling may occur throughout the heart and ischaemic cardiac disease can potentially promote nerve sprouting and increase the incidence and duration of atrial fibrillation and ventricular arrhythmias [18].

Tan et al. have provided insights into the role of autonomic nerve activity in atrial arrhythmogenesis using animal models. They induced heart failure in canine hearts with ventricular pacing and found that both stellate ganglion and vagal nerve activity were stimulated [19]. Increased nerve activity was directly associated with paroxysmal atrial tachycardia (PAT) in these dogs. Subsequently, a canine model of intermittent atrial tachy-pacing was developed, with rapid atrial pacing for 6-7 days, followed by one non-paced day to examine PAT and paroxysmal atrial fibrillation (PAF) without pacing artifacts. Intermittent left atrial (LA) tachy-pacing caused sympathetic hyperinnervation, PAF and PAT. Simultaneous sympatho-vagal discharges often precede the onset of arrhythmias and likely represent the relevant trigger. About $73 \%$ of PAT and PAF episodes were preceded by simultaneous sympatho-vagal discharges in this study [19]. 
Optical mapping data showed $\mathrm{Ca} 2+$-initiated triggered activity in atrial arrhythmogenesis resulting from parasympathetic activation in transgenic mice that develop a fibrotic AF-substrate due to overexpression of constitutively-activated transforming growth-factor (TGF)- $\beta$ [20]. These findings are consistent with a previous study [21] that showed AF-induction by simultaneous acetylcholine and isoproterenol infusion into the sinus node artery of anesthetized dogs. Direct recordings from both the extrinsic nervous system and the intrinsic cardiac nervous system were performed to distinguish their roles in the development of AF [22]. After intermittent rapid atrial pacing, ambulatory dogs displayed spontaneous PATs before the development of persistent AF. Atrial tachyarrhythmias were consistently preceded by intrinsic cardiac nerve activity. These findings further support the importance of autonomic ganglia in the pathogenesis of AF associated with atrial tachycardia [23]. Since histological studies show extensive co-localization of adrenergic and cholinergic nerve structures in the intrinsic cardiac nerves [14], it is possible that the simultaneous activation of these two arms of the autonomic nervous system may be involved in arrhythmia initiation.

\section{Evidence for protective effects of centrally acting sympatholytic agents - a role of moxonidine in reducing sympathetic nervous system overflow and AF burden?}

Atrial fibrillation is the most frequent sustained cardiac arrhythmia in humans and it often complicates the natural history of hypertensive patients $[24,25]$. Several studies have shown that the interaction between electrical remodelling of the atria and the autonomic nervous system can induce and maintain AF [19, 3, 26, 27]. Increased parasympathetic activation leads to shortening of the atrial effective refractory period (AERP), creating a substrate for re-entries, whereas sympathetic tone enhances spontaneous triggered activity [28]. The predominant autonomic cause sympathetic or vagal - seems to depend on the presence of cardio-vascular comorbidities [29]. Patients with hypertension, coronary artery disease, obstructive sleep apnoea (OSA) and heart failure typically show an elevated sympathetic tone, while the parasympathetic hyperactivation is more common in the absence of organic heart disease [26]. Recent studies have suggested that combined overactivation of both the sympathetic and parasympathetic limbs of the autonomic system may be responsible for AF episodes. Furthermore, it has been shown that an increase in adrenergic tone followed by a marked modulation toward vagal predominance preceded episodes of paroxysmal $\mathrm{AF}$ in both patients with isolated paroxysmal $\mathrm{AF}$ and those with structural heart disease [30]. 
Based on the considerable evidence that the autonomic system plays an important role in the pathogenesis of atrial fibrillation, studies have explored the utility of centrally acting sympathoinhibitory agents such as moxonidine in modulating elevated sympathetic drive.

Moxonidine is a centrally acting sympatho-inhibitory agent that acts predominantly through stimulation of the I1-imidazoline receptor. It is a second generation antihypertensive agent with a well established blood pressure lowering effect of 24-h duration [31-35]. Leprán et al. investigated the influence of moxonidine on arrhythmias induced by myocardial ischemia and reperfusion injury in conscious rats [36]. Moxonidine significantly decreased the incidence of ventricular tachycardia and other arrhythmias. In a subsequent study, Mest and Colleagues [37] found that moxonidine significantly increased the threshold dose of ouabain needed to induce ventricular arrhythmias and asystole in guinea pigs in a dose-dependent fashion. The ouabain-induced cardiac arrhythmia was associated with increased sympathetic tone. Clonidine, a centrally acting $\alpha 2$-adrenoreceptor agonist, also increased the threshold dose of ouabain necessary to induce arrhythmias, but was less effective than moxonidine. Moxonidine also reduced aconitine-induced extrasystoles (ES) in the spontaneously beating guinea pig auricle.

Based on these preclinical findings, Deftereos et al. tested the hypothesis that a moxonidine-induced reduction of sympathetic activation could decrease AF burden in hypertensive patients with paroxysmal AF [38]. In this prospective, double-blind, single-group, crossover study, 60 patients were treated with moxonidine in addition to their pre-existing medication regimen. The primary and secondary outcomes were AF burden and episodes per day, respectively. AF burden was $41 \%$ less in the moxonidine treatment phase, compared with the placebo treatment period, and the difference between the two treatment periods was significant even if an independent comparison was performed $(\mathrm{p}=0.01)$. Moreover, AF burden reduction was not related to gender $(\mathrm{p}=0.52)$ or to diastolic blood pressure levels $(\mathrm{p}=0.72)$. A significant reduction in the number of AF episodes per day was observed, together with a reduction in the severity of AF-related symptoms. Moxonidine treatment was not associated with any serious adverse effects.

A subsequent randomized, controlled study by the same group tested the hypothesis that moxonidine could reduce post-ablation recurrence of AF in patients with hypertension undergoing pulmonary vein isolation for drug-refractory paroxysmal AF [39]. After a run-in period, 296 patients underwent AF ablation with pulmonary vein isolation, having started the treatment 1 week before ablation with an initial dose of moxonidine of $0.2 \mathrm{mg}$ daily. The dose was increased to 0.4 $\mathrm{mg}$ daily (0.2 mg twice daily) after 3 weeks, if tolerated. AF recurred in 55/144 patients in the 
control group vs 38/147 patients in the moxonidine group (unadjusted hazard ratio, 0.56 [95\% CI, 0.37-0.86]; $P=0.007)$. While there was no statistically significant difference in terms of blood pressure (BP) reduction between the two groups, a lowering of $-3.1 /-0.9 \mathrm{mmHg}$ in mean systolic/diastolic blood pressure (SBP/DBP) from baseline to 3 months was observed in the moxonidine group compared to placebo $(\mathrm{p}<0.001$ and $\mathrm{p}<0.01$, respectively). Patients with AF recurrence were older, with higher body mass index, more episodes of AF in the past year, and higher systolic blood pressure (SBP) at baseline $(140.3 \pm 8.3$ moxonidine group vs $138.7 \pm 7.8 \mathrm{mmHg}$ in the control group; DBP at baseline: $82.4 \pm 6.5$ moxonidine group vs $82.1 \pm 6.7 \mathrm{mmHg}$ in the control group). Left atrial size and left ventricular ejection fraction were also associated with recurrence. In the primary outcome analysis, there was an early and significant divergence of the recurrence-free survival curves in the two treatment arms was observed $(p=0.006)$. The moxonidine effect was homogeneous across analysed subgroups, e.g., elderly versus younger patients $(P=0.07)$, men versus women $(P=0.5)$, high versus low body mass index $(P=0.6)$, and diabetics versus nondiabetics $(P=0.55)$. The rate of death or hospitalization for any cause was similar, and the frequency of potentially-associated treatment adverse effects did not differ in the 2 treatment arms, with the exception of xerostomia [40]. These studies support the notion that moxonidine-induced reduction in sympathetic drive is effective in reducing AF burden in hypertensive patients and AF recurrence rates in patients who underwent $\mathrm{AF}$ ablation for symptomatic $\mathrm{AF}$.

The concept of interfering with the autonomic tone to prevent AF recurrences or to reduce arrhythmia burden by the suppression of central adrenergic stimulation is interesting. Moxonidine is a centrally acting agent that reduces the levels of central sympathetic tone, resulting in suppression of atrial arrhythmogenesis [41]. However, as the authors noted that these results should not be extrapolated to the general population of patients affected by AF, e.g. patients with impaired ventricular function, (who were excluded in this trial if LV ejection fraction was $<40 \%$ ) based on previous results of the "Moxonidine in Congestive Heart Failure [MOXCON] Trial" [42, 43], in which moxonidine was found to increase mortality in patients with heart failure (HF) and an LV ejection fraction of $<35 \%$. While it remains unresolved why in the MOXCON trial more people in the moxonidine group compared to the control group experienced the primary outcome, it is likely that the very high dose used in the trial (up to $3 \mathrm{~g} / \mathrm{d}$, i.e $5 \mathrm{x}$ as much as the currently recommended maximum dose of $0.6 \mathrm{mg}$ for hypertension treatment) and the forced up-titration that was part of the protocol may well account for these findings [42]. On this background it would seem appropriate to initiate a study to re-investigate whether smaller doses and slow up-titration to $0.4-0.6 \mathrm{mg} / \mathrm{d}$ of moxonidine may have a beneficial effect in HF patients. Parallels could be drawn to the 
contemporary use of beta-blockers in HF, which are commonly initiated at the lowest dose and cautiously up-titrated. National and international HF treatment guidelines suggest such a "step by step" sympathetic system blockage [44]. While enhanced central sympathetic outflow is an indicator of the prognosis of HF the benefits of monoxidine in hypertensive HF remain poorly understood, and studies to better define its therapeutic role in that patient population are still ongoing $[41,45,46]$.

\section{The role of moxonidine in blocking the SNA is probably not limited to AF}

The sympathetic nervous system plays a central role in the pathophysiology not only of hypertension and other cardiovascular disorders, but also obesity, which is often accompanied by abnormalities in glucose and lipid metabolism. Autonomic dysfunction may be one of the early pathophysiological changes that precedes the development of insulin-resistance and obesity, as shown in offspring studies and prospective cohort studies [47-51]. Sympathetic activation often occurs in presence of excessive visceral fat accumulation [52-56]. In experimental settings, visceral fat has been shown to secrete a large number of adipokines, cytokines, and bioactive mediators capable of stimulating the SNS [57]. Whether sympathetic activation is a cause or a consequence of obesity remains the subject of debate.

The relationship between abdominal obesity, the metabolic syndrome and the development of AF is well established. Further, recent studies have shown clear associations between epi / pericardial adipose tissue and AF, suggesting that epicardial fat could increase the risk of developing cardiovascular disease, given its direct proximity to the heart [58-60]. Epicardial fat is distributed irregularly between the visceral pericardium and the myocardium and could reach the atrioventricular and interventricular grooves and right ventricular lateral wall. The sum of the fat deposited outside the parietal pericardium (also called "intrathoracic fat") and the epicardial fat is described as pericardial fat. An increase of pericardial fat is correlated with "lipomatous septal hypertrophy", a condition characterized by localized increases in atrial septal fat and historically associated with sick sinus syndrome and atrial arrhythmias [61-64]. A Study by Al Chekakie et al. demonstrated an association between pericardial fat and both paroxysmal and persistent AF ( $\mathrm{p}<$ 0.001) that was independent of all other major AF risk factors, including LA enlargement. Pericardial fat volume was significantly larger in patients with paroxysmal AF compared with those in sinus rhythm $(\mathrm{p}=0.02)$, and was larger yet in those with persistent AF compared with the paroxysmal AF group $(\mathrm{p}=0.001)[65]$. 
Two recent cross-sectional analyses of Framingham Heart Study data have provided new insight into the relationship between epicardial fat and AF. Thanassoulis et al observed, in a middle-aged to elderly community-based cohort, that higher pericardial fat volumes were associated with about $40 \%$ higher odds of prevalent AF. This association remained significant after adjustment for body mass index (BMI), HF, myocardial infarction and other regional fat depots [66]. A more recent analysis by Friedman et al, conducted on 1946 subjects, showed that pericardial fat was associated with abnormalities in atrial conduction (PR interval, P-duration, P-amplitude and P-terminal) as quantified by $\mathrm{P}$ wave indices (PWI), even with adjustment for extra-cardiac fat depots [67].

A Study by Chao et al. enrolled 227 paroxysmal AF and 56 non-paroxysmal AF patients who received radiofrequency catheter ablation for the first time [68]. The trial showed that epicardial adipose tissue was thicker in non-PAF than PAF patients, suggesting associations with AF chronicity and progression, as previously discussed [65]. The authors concluded that epicardial adipose tissue thickness, measured by trans-thoracic echocardiography, could be a convenient parameter to predict recurrences after catheter ablation of AF [68]. Another trial confirmed the association between the presence of AF, AF chronicity, poorer outcomes after AF ablation and pericardial fat volumes (all, $\mathrm{p}<0.005$ ) assessed by cardiac magnetic resonance in a population of 110 patients undergoing first-time AF ablation and 20 control patients [69].

Infiltration of adipocytes from the epicardial fat into the myocardial wall appears to be a key mechanism underlying the association between pericardial fat and AF. Some studies have shown that increased pericardial fat is associated with significant increases in left ventricular mass, impaired diastolic function and left atrial dimensions [70]. In addition, enlargement of the ventricular myocardium and atrial septum associated with marked fatty infiltration may lead to electromechanical changes in atrial tissue. It is well established that pericardial fat represents a local source of inflammatory cytokines, including tumor necrosis factor-alpha and interleukin-6, which have "paracrine actions" such as direct arrhythmogenic effects on atrial tissue [71-74] (Figure 2). These findings, if confirmed, suggest that pericardial fat may represent a novel risk factor for AF. Further, recent studies have identified an association between epicardial fat and the presence and severity of CAD $[75,76]$.

Pharmacological approaches to directly or indirectly target SNS overactivity may reduce the cardiometabolic consequences of autonomic dysfunction. For example, a double-blind, placebocontrolled Study by Haenni et al [77] that treated 77 patients with essential hypertension and body 
mass index $>27 \mathrm{~kg} / \mathrm{m}^{2}$ for $8-9$ weeks with moxonidine or placebo demonstrated improvment in insulin-sensitivity in insulin-resistant patients, but not in insulin-sensitive patients with moxonidine compared to placebo. The CAMUS Study [78], was a post-marketing surveillance trial that assessed the BP lowering effects of moxonidine in 4005 hypertensive patients who were overweight and/or had the metabolic syndrome. Patients were begun on moxonidine treatment and followed up for 8 weeks. At the end of follow-up, there were marked reductions in systolic (26.9 $\pm 15.1 \mathrm{mmHg} ; 95 \% \mathrm{CI}: 26.4-27.3)$ and diastolic (13.2 $\pm 9.5 \mathrm{mmHg}$; 95\% CI: 12.9-13.5) blood pressures that were greatest in patients with the highest baseline blood pressures.. Blood pressure reductions were similar in patients with and without the metabolic syndrome [79]. At the end of the 8-week observation period, patients lost an average of $1.4+2.9 \mathrm{~kg}(0.5+1.0 \mathrm{~kg} / \mathrm{m} 2$ BMI change). This change was independent of sex or the presence of the metabolic syndrome. The reduction in body weight was greater in obese $(-1.8 \pm 3.5 \mathrm{~kg})$ vs normal-weight $(-0.0 \pm 1.9 \mathrm{~kg})$ or overweight patients $(-1.1 \pm 2.1 \mathrm{~kg})$.

In a subsequent study the effects of monoxidine vs. metformin on glycaemic control were assessed in patients with impaired glucose tolerance and signs of the metabolic syndrome. Moxonidine improved insulin sensitivity in an oral glucose tolerance test (OGTT) by reducing plasma insulin levels. These effects were most marked in patients with high sympathetic outflow at baseline. These findings were confirmed by the results of the MERSY study [80], a multinational, open-label, observational study in a real world scenario in primary care practice. The objective of the trial was to assess the effect of long-term moxonidine treatment on laboratory parameters associated with the metabolic syndrome in hypertensive patients. There was a clear trend of improvement in most metabolic parameters (i.e plasma glucose was reduced on average by $0.8 \mathrm{mmol} / \mathrm{L}$; TG were reduced by $0.6 \mathrm{mmol} / \mathrm{L}$ ). An average weight loss of $-2.1 \pm 5.4 \mathrm{~kg}$ and an average reduction in BMI of -0.7 $\pm 2.0 \mathrm{~kg} / \mathrm{m}^{2}$ were observed. While uncontrolled and therefore less robust than randomized controlled trial data, these observational data, togehter with results of the other smaller randomized controlled studies mentioned above cleary indicate that sympatholytic therapy with moxonidine is associated with both improved BP control and beneficial effects on clinically relevant metabolic markers. More appropriately designed trials are needed to test whether pharmacological sympathetic inhibition is effective in preventing or reversing cardiometabolic disorders, including atrial fibrillation, in obese patients.

\section{The potential role of renal denervation}


A variety of interventional treatment modalities aimed at modulating the autonomic nervous system and interfering with imbalances in the intrinsic cardiac nervous system believed to be involved in the pathogenesis of AF have emerged in recent years [81]. For example, radiofrequency (RF) catheter ablation therapy by means of pulmonary vein isolation (PVI) is an effective and well established treatment for symptomatic AF [25]. However, the rate of recurrence of atrial tachyarrhythmias after a single procedure remains releatively high, ranging from $15-60 \%$ after 1 year and 50-70\% after 5 years, depending on patient selection and on the type of AF and prevalence of comorbidities, including uncontrolled hypertension $[82,83]$. The main mechanism involved in AF recurrence after PVI is pulmonary vein reconnection. As shown in several studies, post-ablation neuromodulation of cardiac innervation and electroanatomical remodelling of the atria are likely contributors.

Catheter-based renal denervation $(\mathrm{RDN})$ is an interventional therapeutic approach aimed at reducing sympathetic activity and blood pressure in resistant hypertensive patients [84-90] (Figure 1). Among its effects are possible improvments in the severity of obstructive sleep apnea and glucose metabolism in this group of patients [91-93]. Due to its effects on sympathetic tone, RDN has also been investigated as a potential additional treatment option for patients with AF, the idea being that RDN induced reduction in overall sympathetic drive may be of benefit in the context of AF. In a preclinical Study by Linz [94], the effects of RDN compared with $\beta$-blockade on atrial electrophysiological changes, AF inducibility, and blood pressure during obstructive events and on shortening of the atrial effective refractory period (AERP) induced by high-frequency stimulation of ganglionated plexi were investigated in 20 anesthetized pigs. RDN reduced AF negative tracheal pressure-induced AF-inducibility $(\mathrm{p}=0.0001)$ and attenuated NTP induced AERP shortening more than the $\beta$ - blocker $(\mathrm{p}=0.0272)$ as opposed to atenolol which did not [94]. Subsequently, the same group investigated the effect of RDN on AF-induced shortening of the AERP, AF inducibility, and ventricular rate control during AF maintained by rapid atrial pacing in 12 pigs undergoing RDN or sham procedure [95]. During sinus rhythm, RDN reduced heart rate $(p=0.0021)$ and increased atrioventricular node conduction time $(\mathrm{p}=0.0001)$. RDN reduced ventricular rate during AF episodes $(p=0.0001)$ and AF episodes were shorter after RDN compared with the sham group $(\mathrm{p}=0.0091)$, even if the AERP remained unchanged after RDN.

The first studies to evaluate the effects of RDN on HR and other electrocardiographic parameters in humans found significant differences in sympathetic cardiac tone post treatment. Heart rate variability was significantly improved at 3 months post RDN [96]. The first clinical evidence of an 
effect of RDN in patients with AF came from Pokushalov et al [97]. This prospective randomized double-blind study assessed the impact of adding RDN to PVI to prevent recurrence of AF in 27 patients with a history of symptomatic paroxysmal and/or persistent AF and drug-resistant hypertension. Patients were randomized to PVI only $(n=14)$ or PVI with RDN $(n=13)$. The primary endpoint of the study was recurrence of $>30$ s of atrial tachyarrhythmia, including AF and left atrial flutter/tachycardia, after a single ablation procedure on no antiarrhythmic drugs. Any arrhythmia that occurred during the "blanking period" (the first 3 months after ablation) was excluded from the analysis [98]. The secondary endpoints were office blood pressure and safety data before and at 3, 6, 9, and 12 months. All patients were treated with antiarrhythmic drugs (propafenone or flecainide) for 6 weeks after PVI; these drugs were subsequently withdrawn, regardless of the cardiac rhythm, to prevent their influence after the blanking period. At the 12month follow-up examination, $9(69 \%)$ of the PVI with RDN group patients were AF-free, while in the PVI-only group, just 4 (29\%) patients were AF-free on no antiarrhythmic drugs $(\mathrm{p}=0.033)$. The patients who underwent PVI only showed no significant changes in blood pressure. By contrast, as anticipated, patients treated with RDN displayed a significant and sustained decrease in systolic and diastolic blood pressure.

These initial positive results triggered initiation of several clinical trials to further investigate the potential adjunctive effect of RDN to PVI in AF. In the H-FIB study [99], a multicenter prospective, double-blind, randomized controlled trial, hypertensive patients with symptomatic paroxysmal or pesistent AF are randomized to either AF ablation alone or in combination with RDN. The primary efficacy endpoint is antiarrhythmic drug-free freedom from AF recurrence through 12 months. The study is currently ongoing and the estimated study completion date is July 2017 [100]. The RSDforAF trial [101] is a randomized, single-blind, parallel-control, multicenter clinical trial designed to compare RDN with antiarrhythmic drugs in patients with resistant hypertension and symptomatic AF. The primary objective of the study, which is planned to enroll up to 200 patients in 6 medical centers in China, is to assess the effects of RDN on both AF burden and blood pressure.

A recent analysis from two randomized studies showed that RDN, when added to PVI to prevent $\mathrm{AF}$ recurrence, is potentially more effective in resistant hypertensive patients than in moderate hypertension [102]. At 1 year follow-up 26 of the 41 PVI with RDN patients (63\%) were AF-free vs 16 of the 39 patients $(41 \%)$ in the PVI-only group $(\mathrm{p}=0.014)$. In patients with severe hypertension, PVI + RDN vs PVI-only was significant $(\mathrm{p}=0.03$ ), whereas for moderate hypertension, the 
differences were less pronounced and did not reach statistical significance, $\mathrm{p}=0.19$. In a case report, the AF conversion to sinus rythm has been reported in a resistant hypertensive patient affected by persitant $\mathrm{AF}$ and referred for RDN to improve BP control without concomitant PVI. Three months later, the patient reported marked improvement in symptoms and exercise capacity although she had amiodarone discontinuation due to intolerance [103]. Emerging evidence has shown that RDN could be an adjunctive therapy for refractory VT in patients with underlying cardiomyopathy. Ukena reported a first-in-man experience in 2 patients with chronic heart failure (non-obstructive hypertrophic and dilated cardiomyopathy, NYHA III) and electrical storm, in which RDN was performed as an attempt to reduce VT occurrence [104]. The patient with hypertrophic cardiomyopathy had persistent monomorphic ventricular tachycardia despite extensive antiarrhythmic therapy and repeated endo- and epicardial ablation in the left ventricle. The second patient suffered from recurrent episodes of polymorphic ventricular tachycardia and ventricular fibrillation but declined catheter ablation. Following RDN, ventricular tachyarrhythmias were significantly reduced in both patients (no more episodes in the second patient). Recently Scholz [105] reported a case of a patient with dilated cardiomyopathy presenting to a chest pain unit with VT storm, refractory to endocardial and epicardial catheter ablation, in whom RDN was performed safely in an emergency setting without any significant effect on blood pressure estimated glomerular filtration rate. During a 5-month follow-up, the patient experienced only one more episode that required ICD therapy, most likey was due to inappropriate prolongation of the QTc interval caused by administration of clarithromycin. These case series, together with the previous mentioned data by Linz [95], contribute to a better understanding of the pathophysiologic consequences of increased renal sympathetic activity. Results from three ongoing prospective clinical trials (RESCUE-VT, RESET-VT and ARDEVAT) will needed to confirm these potential beneficial effects of RDN [106-108].

\section{Conclusions}

Overactivation of the sympathetic nervous system, detectable by increased muscle sympathetic nerve activity (MSNA) and renal noradrenaline spillover, leads to increased levels of plasma catecholamines and contributes to blood pressure elevation. Activation of the sympathetic nervous system also plays an important role in the pathogenesis of comorbidities related to hypertension, such as AF, congestive heart failure, obesity, insulin resistance, and obstructive sleep apnea [109, 110]. Methods that reduce autonomic innervation or outflow, such as centrally acting sympathoinhibitory agents, have been shown to reduce the incidence of spontaneous or induced atrial arrhythmias, suggesting that neuromodulation may be helpful in controlling AF. Moxonidine, a second-generation centrally acting antihypertensive drug, reduces the activity of the sympathetic 
nervous system by activating I 1 imidazoline receptors in the rostal ventrolateral medulla (RVLM) [111]. The result is inhibition of peripheral alpha-adrenergic tone and blood pressure reduction due

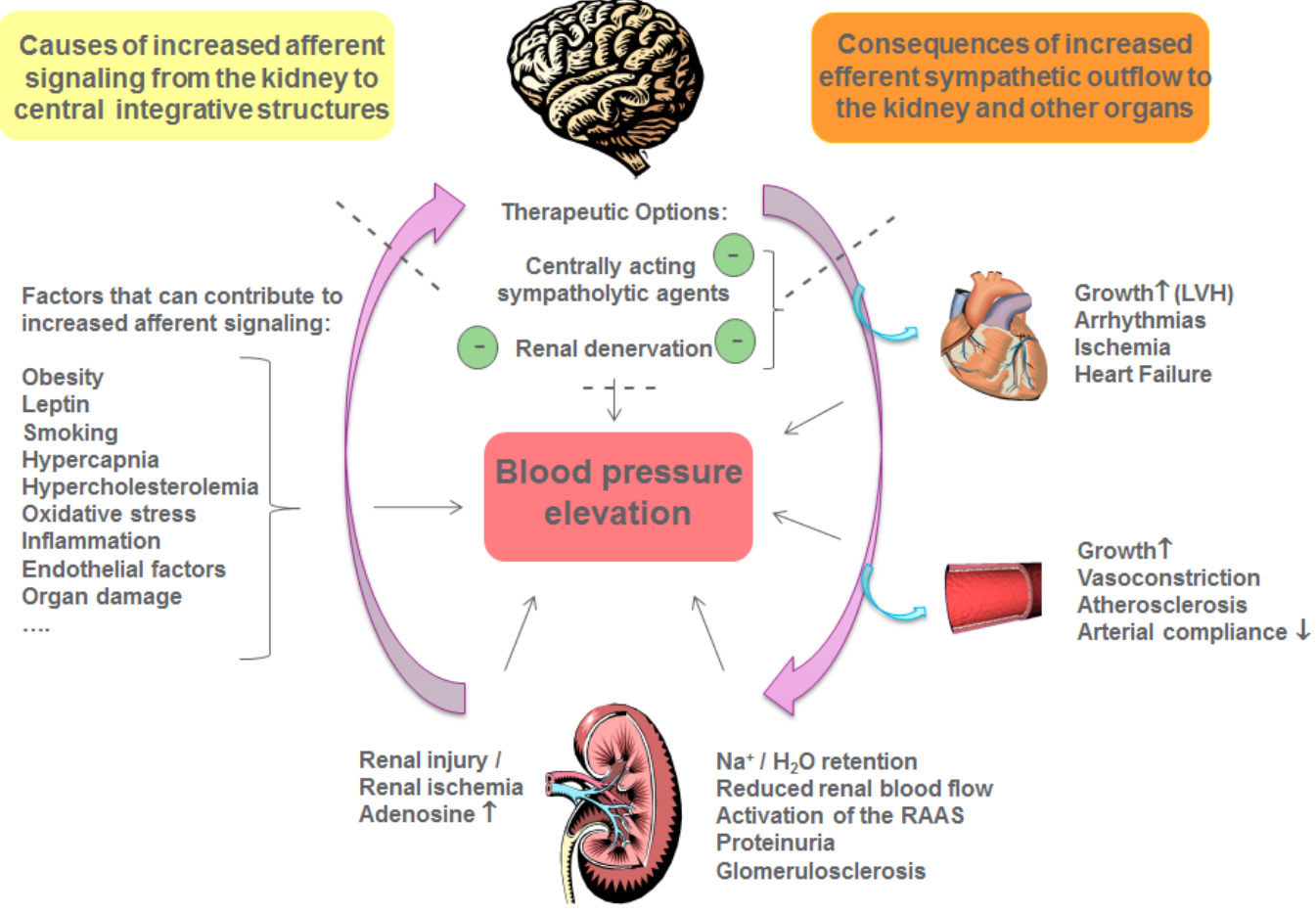

to a fall in systemic vascular resistance [112]. Preclinical studies convincingly demonstrated a decreased incidence of ventricular tachycardia and arrhythmias either induced by myocardial ischemia or reperfusion injury in rats. Subsequent clinical trials confirmed that moxonidine could decrease AF burden in hypertensive patients with paroxysmal AF and reduce post-ablation recurrence of $\mathrm{AF}$ in patients with hypertension who are undergoing pulmonary vein isolation [38, 39]. A number of randomized clinical studies have investigated the effects of RDN on preventing AF recurrence when added to PVI. Several ongoing trials will provide relevant and eagerly awaited information about its potential role in the management and prevention of AF in hypertensive patients.

\section{FIGURES}

Figure 1: Catheter-based renal denervation $(\mathrm{RDN})$ is a new interventional therapeutic approach aimed to reduce sympathetic activity and blood pressure in resistant hypertensive patients (modified from Schlaich M. Hypertension. 2011;57:683-685). 


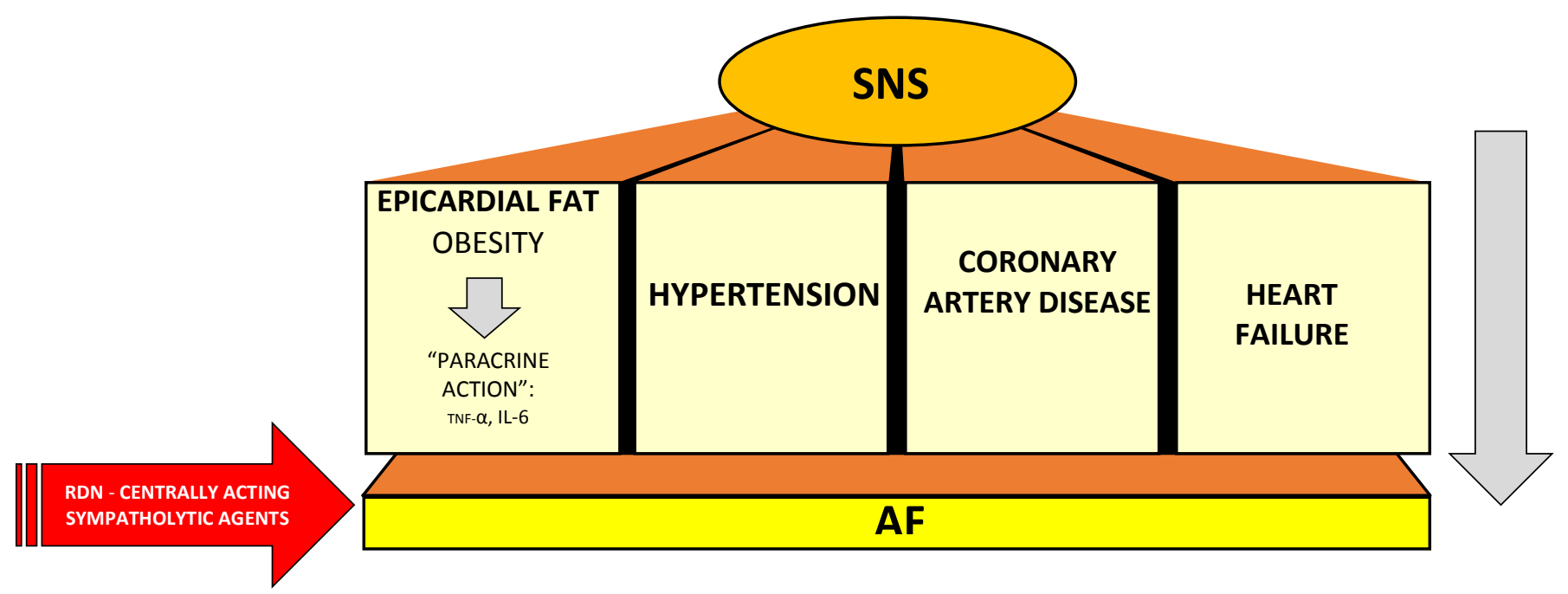

Figure 2: Activation of the sympathetic nervous system plays a fundamental role in the pathogenesis of comorbidities related to the development AF, such as obesity (and particularly epicardial fat with its "paracrine action"), hypertension, coronary artery disease and heart failure. Renal denervation and sympatholytic drugs may control AF via a reduction in sympathetic outflow. 


\section{Compliance with Ethics Guidelines}

Not applicable since this is a review article.

\section{Disclosures / Conflict of Interest}

Dr Schlaich is supported by career fellowships from the NHMRC, is an investigator in studies sponsored by Medtronic, serves on scientific advisory boards for Abbott (formerly Solvay) Pharmaceuticals, BI, Novartis Pharmaceuticals, and Medtronic and has received honoraria and travel support from Abbott, BI, Servier, Novartis and Medtronic. All other authors have no conflict of interest to declare.

\section{Human and Animal Rights and Informed Consent}

This article does not contain any studies with human or animal subjects performed by any of the authors. 


\section{REFERENCES}

\section{Papers of particular interest, published recently, have been highlighted as: • Of importance •• Of major importance}

1. Chugh SS, Havmoeller R, Narayanan K, Singh D, Rienstra M, Benjamin EJ et al. Worldwide epidemiology of atrial fibrillation: a Global Burden of Disease 2010 Study. Circulation. 2014;129(8):837-47. doi:10.1161/circulationaha.113.005119.

2. Ardell JL. The cardiac neuronal hierarchy and susceptibility to arrhythmias. Heart Rhythm. 2011;8(4):590-1. doi:10.1016/j.hrthm.2010.12.019.

3. Chen PS, Tan AY. Autonomic nerve activity and atrial fibrillation. Heart Rhythm. 2007;4(3 Suppl):S61-4. doi:10.1016/j.hrthm.2006.12.006.

4. Janes RD, Brandys JC, Hopkins DA, Johnstone DE, Murphy DA, Armour JA. Anatomy of human extrinsic cardiac nerves and ganglia. Am J Cardiol. 1986;57(4):299-309.

5. Armour J, Hopkins D. Anatomy of the extrinsic efferent autonomic nerves and ganglia innervating the mammalian heart. In: Press NYOU, editor. Nervous control of cardiovascular function., 1984. p. 21-45.

6. Kawashima T. The autonomic nervous system of the human heart with special reference to its origin, course, and peripheral distribution. Anat Embryol (Berl). 2005;209(6):425-38. doi:10.1007/s00429-005-0462-1.

7. Baron R, Janig W, With H. Sympathetic and afferent neurones projecting into forelimb and trunk nerves and the anatomical organization of the thoracic sympathetic outflow of the rat. $\mathrm{J}$ Auton Nerv Syst. 1995;53(2-3):205-14.

8. Ellison JP, Williams TH. Sympathetic nerve pathways to the human heart, and their variations. Am J Anat. 1969;124(2):149-62. doi:10.1002/aja.1001240203.

9. Page PL, Dandan N, Savard P, Nadeau R, Armour JA, Cardinal R. Regional distribution of atrial electrical changes induced by stimulation of extracardiac and intracardiac neural elements. J Thorac Cardiovasc Surg. 1995;109(2):377-88.

10. Taniguchi T, al. e. Cutaneous distribution of sympathetic postganglionic fibers from stellate ganglion: A retrograde axonal tracing study using wheat germ agglutinin conjugated with horseradish peroxidase. J Anesth. 1994;8:441-9.

11. Shen MJ, Hao-Che C, Park HW, George Akingba A, Chang PC, Zheng Z et al. Low-level vagus nerve stimulation upregulates small conductance calcium-activated potassium channels in the stellate ganglion. Heart Rhythm. 2013;10(6):910-5. doi:10.1016/j.hrthm.2013.01.029.

12. Ogawa M, Zhou S, Tan AY, Song J, Gholmieh G, Fishbein MC et al. Left stellate ganglion and vagal nerve activity and cardiac arrhythmias in ambulatory dogs with pacing-induced congestive heart failure. Journal of the American College of Cardiology. 2007;50(4):335-43. doi:10.1016/j.jacc.2007.03.045.

13. Chen PS, Chen LS, Fishbein MC, Lin SF, Nattel S. Role of the autonomic nervous system in atrial fibrillation: pathophysiology and therapy. Circulation research. 2014;114(9):1500-15. doi:10.1161/circresaha.114.303772.

14. Tan AY, Li H, Wachsmann-Hogiu S, Chen LS, Chen PS, Fishbein MC. Autonomic innervation and segmental muscular disconnections at the human pulmonary vein-atrial junction: implications for catheter ablation of atrial-pulmonary vein junction. Journal of the American College of Cardiology. 2006;48(1):132-43.

15. Vracko R, Thorning D, Frederickson RG. Nerve fibers in human myocardial scars. Human pathology. 1991;22(2):138-46.

16. Vracko R, Thorning D, Frederickson RG. Fate of nerve fibers in necrotic, healing, and healed rat myocardium. Laboratory investigation; a journal of technical methods and pathology. 1990;63(4):490-501.

17. Cao JM, Chen LS, KenKnight BH, Ohara T, Lee MH, Tsai J et al. Nerve sprouting and sudden cardiac death. Circulation research. 2000;86(7):816-21. 
18. Miyauchi Y, al. e. Induction of atrial sympathetic nerve sprouting and increased vulnerability to atrial fibrillation by chronic left ventricular myocardial infarction. Circulation. 2001;104(II).

19. Tan AY, Zhou S, Ogawa M, Song J, Chu M, Li H et al. Neural mechanisms of paroxysmal atrial fibrillation and paroxysmal atrial tachycardia in ambulatory canines. Circulation. 2008;118(9):916-25. doi:10.1161/circulationaha.108.776203.

20. Viskin S, Golovner M, Malov N, al. e. Circadian variation of symptomatic paroxysmal atrial fibrillation. Data from almost 10000 episodes. . European Heart Journal. 1999;20:1429-34.

21. Sharifov OF, Fedorov VV, Beloshapko GG, Glukhov AV, Yushmanova AV, Rosenshtraukh LV. Roles of adrenergic and cholinergic stimulation in spontaneous atrial fibrillation in dogs. Journal of the American College of Cardiology. 2004;43(3):483-90. doi:10.1016/j.jacc.2003.09.030.

22. Liu L, Nattel S. Differing sympathetic and vagal effects on atrial fibrillation in dogs: role of refractoriness heterogeneity. The American journal of physiology. 1997;273(2 Pt 2):H805-16.

23. Nishida K, Maguy A, Sakabe M, Comtois P, Inoue H, Nattel S. The role of pulmonary veins vs. autonomic ganglia in different experimental substrates of canine atrial fibrillation. Cardiovascular research. 2011;89(4):825-33. doi:10.1093/cvr/cvq332.

24. Marini C, De Santis F, Sacco S, Russo T, Olivieri L, Totaro R et al. Contribution of atrial fibrillation to incidence and outcome of ischemic stroke: results from a population-based study. Stroke; a journal of cerebral circulation. 2005;36(6):1115-9. doi:10.1161/01.STR.0000166053.83476.4a.

25. Camm AJ, Kirchhof P, Lip GY, Schotten U, Savelieva I, Ernst S et al. Guidelines for the management of atrial fibrillation: the Task Force for the Management of Atrial Fibrillation of the European Society of Cardiology (ESC). European heart journal. 2010;31(19):2369-429. doi:10.1093/eurheartj/ehq278.

26. Scherlag BJ, Patterson E, Po SS. The neural basis of atrial fibrillation. Journal of electrocardiology. 2006;39(4 Suppl):S180-3. doi:10.1016/j.jelectrocard.2006.05.021.

27. Wijffels MC, Kirchhof CJ, Dorland R, Power J, Allessie MA. Electrical remodeling due to atrial fibrillation in chronically instrumented conscious goats: roles of neurohumoral changes, ischemia, atrial stretch, and high rate of electrical activation. Circulation. 1997;96(10):371020.

28. Moe GK, Abildskov JA. Atrial fibrillation as a self-sustaining arrhythmia independent of focal discharge. American heart journal. 1959;58(1):59-70.

29. Kapa S, Venkatachalam KL, Asirvatham SJ. The autonomic nervous system in cardiac electrophysiology: an elegant interaction and emerging concepts. Cardiology in review. 2010;18(6):275-84. doi:10.1097/CRD.0b013e3181ebb152.

30. Bettoni M, Zimmermann M. Autonomic tone variations before the onset of paroxysmal atrial fibrillation. Circulation. 2002;105(23):2753-9.

31. Head GA. Central imidazoline- and alpha 2-receptors involved in the cardiovascular actions of centrally acting antihypertensive agents. Annals of the New York Academy of Sciences. 1999;881:279-86.

32. Trenk D, Wagner F, Jahnchen E, Planitz V. Pharmacokinetics of moxonidine after single and repeated daily doses in healthy volunteers. Journal of clinical pharmacology. 1987;27(12):988-93.

33. Kraft K, Vetter H. Twenty-four-hour blood pressure profiles in patients with mild-tomoderate hypertension: moxonidine versus captopril. Journal of cardiovascular pharmacology. 1994;24 Suppl 1:S29-33.

34. Kuppers HE, Jager BA, Luszick JH, Grave MA, Hughes PR, Kaan EC. Placebo-controlled comparison of the efficacy and tolerability of once-daily moxonidine and enalapril in mild-tomoderate essential hypertension. Journal of hypertension. 1997;15(1):93-7. 
35. Planitz V. Intraindividual comparison of moxonidine and prazosin in hypertensive patients. European journal of clinical pharmacology. 1986;29(6):645-50.

36. Lepran I, Papp JG. Effect of moxonidine on arrhythmias induced by coronary artery occlusion and reperfusion. Journal of cardiovascular pharmacology. 1994;24 Suppl 1:S9-15.

37. Mest HJ, Thomsen P, Raap A. Antiarrhythmic effect of the selective I1-imidazoline receptor modulator moxonidine on ouabain-induced cardiac arrhythmia in guinea pigs. Annals of the New York Academy of Sciences. 1995;763:620-33.

38. Deftereos S, Giannopoulos G, Kossyvakis C, Efremidis M, Panagopoulou V, Raisakis K et al. Effectiveness of moxonidine to reduce atrial fibrillation burden in hypertensive patients. Am J Cardiol. 2013;112(5):684-7. doi:10.1016/j.amjcard.2013.04.049.

** First study to show that a reduction of sympathetic activation with administration of moxonidine resulted in a decrease in AF burden in hypertensive patients with paroxysmal $A F$.

39. Giannopoulos G, Kossyvakis C, Efremidis M, Katsivas A, Panagopoulou V, Doudoumis K et al. Central sympathetic inhibition to reduce postablation atrial fibrillation recurrences in hypertensive patients: a randomized, controlled study. Circulation. 2014;130(16):1346-52. doi:10.1161/circulationaha.114.010999.

** First study to demonstrate that moxonidine reduce post-ablation recurrence of $A F$ in patients with hypertension who underwent pulmonary vein isolation for drug-refractory paroxysmal $A F$.

40. Schachter M, Luszick J, Jager B, Verboom C, Sohlke E. Safety and tolerability of moxonidine in the treatment of hypertension. Drug safety. 1998;19(3):191-203.

41. Edwards LP, Brown-Bryan TA, McLean L, Ernsberger P. Pharmacological properties of the central antihypertensive agent, moxonidine. Cardiovascular therapeutics. 2012;30(4):199-208. doi:10.1111/j.1755-5922.2011.00268.x.

42. Cohn JN, Pfeffer MA, Rouleau J, Sharpe N, Swedberg K, Straub M et al. Adverse mortality effect of central sympathetic inhibition with sustained-release moxonidine in patients with heart failure (MOXCON). European journal of heart failure. 2003;5(5):659-67.

43. Pocock S, Wilhelmsen L, Dickstein K, Francis G, Wittes J. The data monitoring experience in the MOXCON trial. European heart journal. 2004;25(22):1974-8. doi:10.1016/j.ehj.2004.09.015.

44. McMurray JJ, Adamopoulos S, Anker SD, Auricchio A, Bohm M, Dickstein K et al. ESC Guidelines for the diagnosis and treatment of acute and chronic heart failure 2012: The Task Force for the Diagnosis and Treatment of Acute and Chronic Heart Failure 2012 of the European Society of Cardiology. Developed in collaboration with the Heart Failure Association (HFA) of the ESC. European heart journal. 2012;33(14):1787-847. doi:10.1093/eurheartj/ehs 104.

45. Honda N, Hirooka Y, Ito K, Matsukawa R, Shinohara K, Kishi T et al. Moxonidine-induced central sympathoinhibition improves prognosis in rats with hypertensive heart failure. Journal of hypertension. 2013;31(11):2300-8; discussion 8. doi:10.1097/HJH.0b013e328364a2a1.

46. Ripley DP, Negrou K, Oliver JJ, Worthy G, Struthers AD, Plein S et al. Aortic remodelling following the treatment and regression of hypertensive left ventricular hypertrophy: a cardiovascular magnetic resonance study. Clinical and experimental hypertension (New York, NY : 1993). 2015;37(4):308-16. doi:10.3109/10641963.2014.960974.

47. Huggett RJ, Hogarth AJ, Mackintosh AF, Mary DA. Sympathetic nerve hyperactivity in nondiabetic offspring of patients with type 2 diabetes mellitus. Diabetologia. 2006;49(11):2741-4. doi:10.1007/s00125-006-0399-9.

48. Julius S, Jamerson K. Sympathetics, insulin resistance and coronary risk in hypertension: the 'chicken-and-egg' question. Journal of hypertension. 1994;12(5):495-502.

49. Masuo K, Katsuya T, Kawaguchi H, Fu Y, Rakugi H, Ogihara T et al. Beta2-adrenoceptor polymorphisms relate to obesity through blunted leptin-mediated sympathetic activation. 
American journal of hypertension. 2006;19(10):1084-91. doi:10.1016/j.amjhyper.2006.02.015.

50. Masuo K, Kawaguchi H, Mikami H, Ogihara T, Tuck ML. Serum uric acid and plasma norepinephrine concentrations predict subsequent weight gain and blood pressure elevation. Hypertension. 2003;42(4):474-80. doi:10.1161/01.hyp.0000091371.53502.d3.

51. Palatini P, Vriz O, Nesbitt S, Amerena J, Majahalme S, Valentini M et al. Parental hyperdynamic circulation predicts insulin resistance in offspring: The Tecumseh Offspring Study. Hypertension. 1999;33(3):769-74.

52. Alvarez GE, Beske SD, Ballard TP, Davy KP. Sympathetic neural activation in visceral obesity. Circulation. 2002;106(20):2533-6.

53. Grassi G, Seravalle G, Cattaneo BM, Bolla GB, Lanfranchi A, Colombo M et al. Sympathetic activation in obese normotensive subjects. Hypertension. 1995;25(4 Pt 1):560-3.

54. Huggett RJ, Burns J, Mackintosh AF, Mary DA. Sympathetic neural activation in nondiabetic metabolic syndrome and its further augmentation by hypertension. Hypertension. 2004;44(6):847-52. doi:10.1161/01.HYP.0000147893.08533.d8.

55. Lambert E, Sari CI, Dawood T, Nguyen J, McGrane M, Eikelis N et al. Sympathetic nervous system activity is associated with obesity-induced subclinical organ damage in young adults. Hypertension. 2010;56(3):351-8. doi:10.1161/hypertensionaha.110.155663.

56. Lambert E, Straznicky N, Eikelis N, Esler M, Dawood T, Masuo K et al. Gender differences in sympathetic nervous activity: influence of body mass and blood pressure. Journal of hypertension. 2007;25(7):1411-9. doi:10.1097/HJH.0b013e3281053af4.

57. Lambert EA, Straznicky NE, Dixon JB, Lambert GW. Should the sympathetic nervous system be a target to improve cardiometabolic risk in obesity? American journal of physiology Heart and circulatory physiology. 2015;309(2):H244-58. doi:10.1152/ajpheart.00096.2015.

58. Mahabadi AA, Massaro JM, Rosito GA, Levy D, Murabito JM, Wolf PA et al. Association of pericardial fat, intrathoracic fat, and visceral abdominal fat with cardiovascular disease burden: the Framingham Heart Study. European heart journal. 2009;30(7):850-6. doi:10.1093/eurheartj/ehn573.

59. Iacobellis G, Ribaudo MC, Assael F, Vecci E, Tiberti C, Zappaterreno A et al. Echocardiographic epicardial adipose tissue is related to anthropometric and clinical parameters of metabolic syndrome: a new indicator of cardiovascular risk. The Journal of clinical endocrinology and metabolism. 2003;88(11):5163-8. doi:10.1210/jc.2003-030698.

60. Sarin S, Wenger C, Marwaha A, Qureshi A, Go BD, Woomert CA et al. Clinical significance of epicardial fat measured using cardiac multislice computed tomography. Am J Cardiol. 2008;102(6):767-71. doi:10.1016/j.amjcard.2008.04.058.

61. Heyer CM, Kagel T, Lemburg SP, Bauer TT, Nicolas V. Lipomatous hypertrophy of the interatrial septum: a prospective study of incidence, imaging findings, and clinical symptoms. Chest. 2003;124(6):2068-73.

62. Isner JM, Swan CS, 2nd, Mikus JP, Carter BL. Lipomatous hypertrophy of the interatrial septum: in vivo diagnosis. Circulation. 1982;66(2):470-3.

63. Sato Y, Matsuo S, Kusama J, Kunimasa T, Yoda S, Matsumoto N et al. Lipomatous hypertrophy of the interatrial septum presenting as sick sinus syndrome. International journal of cardiology. 2007;119(2):280-1. doi:10.1016/j.ijcard.2006.07.161.

64. Shirani J, Roberts WC. Clinical, electrocardiographic and morphologic features of massive fatty deposits ("lipomatous hypertrophy") in the atrial septum. Journal of the American College of Cardiology. 1993;22(1):226-38.

65. Al Chekakie MO, Welles CC, Metoyer R, Ibrahim A, Shapira AR, Cytron J et al. Pericardial fat is independently associated with human atrial fibrillation. Journal of the American College of Cardiology. 2010;56(10):784-8. doi:10.1016/j.jacc.2010.03.071.

66. Thanassoulis G, Massaro JM, O'Donnell CJ, Hoffmann U, Levy D, Ellinor PT et al. Pericardial fat is associated with prevalent atrial fibrillation: the Framingham Heart Study. 
Circulation Arrhythmia and electrophysiology. 2010;3(4):345-50. doi:10.1161/circep.109.912055.

** Recent cross-sectional analysis of the Framingham Heart Study showing that higher pericardial fat volumes were associated with about $40 \%$ higher odds of prevalent $A F$.

67. Friedman DJ, Wang N, Meigs JB, Hoffmann U, Massaro JM, Fox CS et al. Pericardial fat is associated with atrial conduction: the Framingham Heart Study. Journal of the American Heart Association. 2014;3(2):e000477. doi:10.1161/jaha.113.000477.

68. Chao TF, Hung CL, Tsao HM, Lin YJ, Yun CH, Lai YH et al. Epicardial adipose tissue thickness and ablation outcome of atrial fibrillation. PloS one. 2013;8(9):e74926. doi:10.1371/journal.pone.0074926.

69. Wong CX, Abed HS, Molaee P, Nelson AJ, Brooks AG, Sharma G et al. Pericardial fat is associated with atrial fibrillation severity and ablation outcome. Journal of the American College of Cardiology. 2011;57(17):1745-51. doi:10.1016/j.jacc.2010.11.045.

70. Fox CS, Gona P, Hoffmann U, Porter SA, Salton CJ, Massaro JM et al. Pericardial fat, intrathoracic fat, and measures of left ventricular structure and function: the Framingham Heart Study. Circulation. 2009;119(12):1586-91. doi:10.1161/circulationaha.108.828970.

71. Mazurek T, Zhang L, Zalewski A, Mannion JD, Diehl JT, Arafat H et al. Human epicardial adipose tissue is a source of inflammatory mediators. Circulation. 2003;108(20):2460-6. doi:10.1161/01.cir.0000099542.57313.c5.

72. 2015. RCMMedce, Study. ABEFTaPCADACC, Faghihi S1 V-FA, Parsaee M3, Saedi S1, Ghadrdoost B1.

73. Marcus GM, Whooley MA, Glidden DV, Pawlikowska L, Zaroff JG, Olgin JE. Interleukin-6 and atrial fibrillation in patients with coronary artery disease: data from the Heart and Soul Study. American heart journal. 2008;155(2):303-9. doi:10.1016/j.ahj.2007.09.006.

74. Tselentakis EV, Woodford E, Chandy J, Gaudette GR, Saltman AE. Inflammation effects on the electrical properties of atrial tissue and inducibility of postoperative atrial fibrillation. The Journal of surgical research. 2006;135(1):68-75. doi:10.1016/j.jss.2006.03.024.

75. Faghihi S, Vasheghani-Farahani A, Parsaee M, Saedi S, Ghadrdoost B. Association Between Epicardial Fat Thickness and Premature Coronary Artery Disease: A Case Control Study. $\begin{array}{llll}\text { Research in medicine. 2015;4(2):e25679. } & \text { cardiovascular }\end{array}$ doi:10.5812/cardiovascmed.4(2)2015.25679.

76. Haberka M, Gasior Z. A carotid extra-media thickness, PATIMA combined index and coronary artery disease: Comparison with well-established indexes of carotid artery and fat depots. Atherosclerosis. 2015;243(1):307-13. doi:10.1016/j.atherosclerosis.2015.09.022.

77. Haenni A, Lithell H. Moxonidine improves insulin sensitivity in insulin-resistant hypertensives. Journal of hypertension Supplement : official journal of the International Society of Hypertension. 1999;17(3):S29-35.

78. Sharma AM, Wagner T, Marsalek P. Moxonidine in the treatment of overweight and obese patients with the metabolic syndrome: a postmarketing surveillance study. Journal of human hypertension. 2004;18(9):669-75. doi:10.1038/sj.jhh.1001676.

79. Chazova I, Almazov VA, Shlyakhto E. Moxonidine improves glycaemic control in mildly hypertensive, overweight patients: a comparison with metformin. Diabetes, obesity \& metabolism. 2006;8(4):456-65. doi:10.1111/j.1463-1326.2006.00606.x.

80. Chazova I, Schlaich MP. Improved Hypertension Control with the Imidazoline Agonist Moxonidine in a Multinational Metabolic Syndrome Population: Principal Results of the MERSY Study. International journal of hypertension. 2013;2013:541689. doi:10.1155/2013/541689.

81. Rajendran PS, Buch E, Shivkumar K. Marshaling the autonomic nervous system for treatment of atrial fibrillation. Journal of the American College of Cardiology. 2014;63(18):1902-3. doi:10.1016/j.jacc.2014.01.033. 
82. Reichlin T, Michaud GF. Our approach to maximizing the durability of pulmonary vein isolation during a paroxysmal atrial fibrillation ablation procedure. Journal of cardiovascular electrophysiology. 2012;23(11):1272-6. doi:10.1111/j.1540-8167.2012.02414.x.

83. Calkins H, Kuck KH, Cappato R, Brugada J, Camm AJ, Chen SA et al. 2012 HRS/EHRA/ECAS expert consensus statement on catheter and surgical ablation of atrial fibrillation: recommendations for patient selection, procedural techniques, patient management and follow-up, definitions, endpoints, and research trial design: a report of the Heart Rhythm Society (HRS) Task Force on Catheter and Surgical Ablation of Atrial Fibrillation. Developed in partnership with the European Heart Rhythm Association (EHRA), a registered branch of the European Society of Cardiology (ESC) and the European Cardiac Arrhythmia Society (ECAS); and in collaboration with the American College of Cardiology (ACC), American Heart Association (AHA), the Asia Pacific Heart Rhythm Society (APHRS), and the Society of Thoracic Surgeons (STS). Endorsed by the governing bodies of the American College of Cardiology Foundation, the American Heart Association, the European Cardiac Arrhythmia Society, the European Heart Rhythm Association, the Society of Thoracic Surgeons, the Asia Pacific Heart Rhythm Society, and the Heart Rhythm Society. Heart Rhythm. 2012;9(4):632-96.e21. doi:10.1016/j.hrthm.2011.12.016.

84. Esler MD, Bohm M, Sievert H, Rump CL, Schmieder RE, Krum H et al. Catheter-based renal denervation for treatment of patients with treatment-resistant hypertension: 36 month results from the SYMPLICITY HTN-2 randomized clinical trial. European heart journal. 2014;35(26):1752-9. doi:10.1093/eurheartj/ehu209.

85. Esler MD, Krum H, Schlaich M, Schmieder RE, Bohm M, Sobotka PA. Renal sympathetic denervation for treatment of drug-resistant hypertension: one-year results from the Symplicity HTN-2 randomized, controlled trial. Circulation. 2012;126(25):2976-82. doi:10.1161/circulationaha.112.130880.

86. Howard JP, Nowbar AN, Francis DP. Size of blood pressure reduction from renal denervation: insights from meta-analysis of antihypertensive drug trials of 4,121 patients with focus on trial design: the CONVERGE report. Heart (British Cardiac Society). 2013;99(21):1579-87. doi:10.1136/heartjnl-2013-304238.

87. Krum H, Schlaich M, Whitbourn R, Sobotka PA, Sadowski J, Bartus K et al. Catheter-based renal sympathetic denervation for resistant hypertension: a multicentre safety and proof-ofprinciple cohort study. Lancet (London, England). 2009;373(9671):1275-81. doi:10.1016/s0140-6736(09)60566-3.

88. Krum H, Schlaich MP, Sobotka PA, Bohm M, Mahfoud F, Rocha-Singh K et al. Percutaneous renal denervation in patients with treatment-resistant hypertension: final 3-year report of the Symplicity HTN-1 study. Lancet (London, England). 2014;383(9917):622-9. doi:10.1016/s0140-6736(13)62192-3.

89. Schlaich MP, Sobotka PA, Krum H, Lambert E, Esler MD. Renal sympathetic-nerve ablation for uncontrolled hypertension. The New England journal of medicine. 2009;361(9):932-4. doi:10.1056/NEJMc0904179.

90. Esler MD, Krum H, Sobotka PA, Schlaich MP, Schmieder RE, Bohm M. Renal sympathetic denervation in patients with treatment-resistant hypertension (The Symplicity HTN-2 Trial): a randomised controlled trial. Lancet (London, England). 2010;376(9756):1903-9. doi:10.1016/s0140-6736(10)62039-9.

91. Mahfoud F, Schlaich M, Kindermann I, Ukena C, Cremers B, Brandt MC et al. Effect of renal sympathetic denervation on glucose metabolism in patients with resistant hypertension: a pilot study. Circulation. 2011;123(18):1940-6. doi:10.1161/circulationaha.110.991869.

92. Sobotka PA, Mahfoud F, Schlaich MP, Hoppe UC, Bohm M, Krum H. Sympatho-renal axis in chronic disease. Clinical research in cardiology : official journal of the German Cardiac Society. 2011;100(12):1049-57. doi:10.1007/s00392-011-0335-y. 
93. Witkowski A, Prejbisz A, Florczak E, Kadziela J, Sliwinski P, Bielen P et al. Effects of renal sympathetic denervation on blood pressure, sleep apnea course, and glycemic control in patients with resistant hypertension and sleep apnea. Hypertension. 2011;58(4):559-65. doi:10.1161/hypertensionaha.111.173799.

94. Linz D, Mahfoud F, Schotten U, Ukena C, Neuberger HR, Wirth K et al. Renal sympathetic denervation suppresses postapneic blood pressure rises and atrial fibrillation in a model for sleep apnea. Hypertension. 2012;60(1):172-8. doi:10.1161/hypertensionaha.112.191965.

95. Linz D, Mahfoud F, Schotten U, Ukena C, Hohl M, Neuberger HR et al. Renal sympathetic denervation provides ventricular rate control but does not prevent atrial electrical remodeling during atrial fibrillation. Hypertension. 2013;61(1):225-31. doi:10.1161/hypertensionaha.111.00182.

96. Himmel F, Weil J, Reppel M, Mortensen K, Franzen K, Ansgar L et al. Improved heart rate dynamics in patients undergoing percutaneous renal denervation. J Clin Hypertens (Greenwich). 2012;14(9):654-5. doi:10.1111/j.1751-7176.2012.00658.x.

97. Pokushalov E, Romanov A, Corbucci G, Artyomenko S, Baranova V, Turov A et al. A randomized comparison of pulmonary vein isolation with versus without concomitant renal artery denervation in patients with refractory symptomatic atrial fibrillation and resistant hypertension. Journal of the American College of Cardiology. 2012;60(13):1163-70. doi:10.1016/j.jacc.2012.05.036.

98. Joshi S, Choi AD, Kamath GS, Raiszadeh F, Marrero D, Badheka A et al. Prevalence, predictors, and prognosis of atrial fibrillation early after pulmonary vein isolation: findings from 3 months of continuous automatic ECG loop recordings. Journal of cardiovascular electrophysiology. 2009;20(10):1089-94. doi:10.1111/j.1540-8167.2009.01506.x.

99. Ahmed H, Miller MA, Dukkipati SR, Cammack S, Koruth JS, Gangireddy S et al. Adjunctive renal sympathetic denervation to modify hypertension as upstream therapy in the treatment of atrial fibrillation (H-FIB) study: clinical background and study design. Journal of cardiovascular electrophysiology. 2013;24(5):503-9. doi:10.1111/jce.12095.

100. Health USNIo. Adjunctive Renal Sympathetic Denervation to Modify Hypertension as Upstream Therapy in the Treatment of Atrial Fibrillation. https://clinicaltrials.gov/ct2/results?term=H-Fib\&Search=Search. Accessed 30 October 2015.

101. Qiu M, Yin Y, Shan Q. Renal sympathetic denervation versus antiarrhythmic drugs for drugresistant hypertension and symptomatic atrial fibrillation (RSDforAF) trial: study protocol for a randomized controlled trial. Trials. 2013;14:168. doi:10.1186/1745-6215-14-168.

102. Pokushalov E, Romanov A, Katritsis DG, Artyomenko S, Bayramova S, Losik D et al. Renal denervation for improving outcomes of catheter ablation in patients with atrial fibrillation and hypertension: early experience. Heart Rhythm. 2014;11(7):1131-8. doi:10.1016/j.hrthm.2014.03.055.

103. Vollmann D, Sossalla S, Schroeter MR, Zabel M. Renal artery ablation instead of pulmonary vein ablation in a hypertensive patient with symptomatic, drug-resistant, persistent atrial fibrillation. Clinical research in cardiology : official journal of the German Cardiac Society. 2013;102(4):315-8. doi:10.1007/s00392-012-0529-y.

104. Ukena C, Bauer A, Mahfoud F, Schreieck J, Neuberger HR, Eick C et al. Renal sympathetic denervation for treatment of electrical storm: first-in-man experience. Clinical research in cardiology : official journal of the German Cardiac Society. 2012;101(1):63-7. doi:10.1007/s00392-011-0365-5.

** A first-in-man experience in 2 patients with chronic heart failure and electrical storm, in which RDN was performed as an experimental attempt to reduce VT occurrence.

105. Scholz EP, Raake P, Thomas D, Vogel B, Katus HA, Blessing E. Rescue renal sympathetic denervation in a patient with ventricular electrical storm refractory to endo- and epicardial catheter ablation. Clinical research in cardiology : official journal of the German Cardiac Society. 2015;104(1):79-84. doi:10.1007/s00392-014-0749-4. 
106. Health USNIo. REnal SympathetiC Denervation to sUpprEss Ventricular Tachyarrhythmias. https://clinicaltrials.gov/ct2/results?term=rescue-vt. Accessed 26 october 2015.

107. Health USNIo. REnal Sympathetic dEnervaTion as an a Adjunct to Catheter-based VT Ablation. https://clinicaltrials.gov/ct2/results?term=RESET-VT\&Search=Search. Accessed 26 october 2015.

108. Health USNIo. Renal Denervation In Patient Undergoing VT Ablation:Combined Renal Denervation and VT Ablation vs. Simply VT Ablation. https://clinicaltrials.gov/ct2/results?term=ardevat\&Search=Search. Accessed 26 october 2015.

109. Esler M, Straznicky N, Eikelis N, Masuo K, Lambert G, Lambert E. Mechanisms of sympathetic activation in obesity-related hypertension. Hypertension. 2006;48(5):787-96. doi:10.1161/01.hyp.0000242642.42177.49.

110. Esler M, In: Zanchetti A, Birkenhager W. Looking at the sympathetic nervous system as a primary source. In: Elsevier, editor. Handbook of Hypertension: Hypertension Research in the Twentieth Century. Amsterdam2004. p. 81-103.

111. Prichard BN, Graham BR, Owens CW. Moxonidine: a new antiadrenergic antihypertensive agent. Journal of hypertension Supplement : official journal of the International Society of Hypertension. 1999;17(3):S41-54.

112. Prichard BN, Graham BR. The use of moxonidine in the treatment of hypertension. Journal of hypertension Supplement : official journal of the International Society of Hypertension. 1997;15(1):S47-55. 